\title{
Fine-scale behaviour of the Lusitanian toadfish assessed in situ with the AccelTag
}

\author{
Tadeu J. Pereira ${ }^{1}$, Pedro R. Almeida ${ }^{1,2}$, Bernardo R. Quintella ${ }^{1,3^{*}} \mathbb{D}$, Aage Gronningsaeter ${ }^{4}$, Maria J. Costa ${ }^{1}$, \\ João P. Marques ${ }^{1}$ and José L. Costa ${ }^{1,3}$
}

\begin{abstract}
Background: Three-axis acceleration sensor acoustic transmitters (AccelTag) programmed to identify specific acceleration patterns associated with particular behaviours (e.g., burrowing, attack) were used to study some aspects of the ecology of the Lusitanian toadfish Halobatrachus didactylus (Bloch \& Schneider 1801). The AccelTag combines the features of archival tags (records acceleration in all three directions measuring also roll-independent pitch/tilt angle and roll around the fish's axis) and acoustic transmitters. Therefore, this tag can autonomously identify and record specific signatures (i.e., behaviour patterns) of different movements transmitting autonomously and periodically the data to an acoustic biotelemetry receiver. Lusitanian toadfish is a subtropical marine teleost confined to estuaries in its northern limit of distribution due to thermal constraints. During 2010 (August and October), 24 toadfish were captured, tagged with the AccelTag and released in the Mira estuary, SW coast of Portugal, where an array of underwater automatic acoustic biotelemetry receivers was deployed.

Results: Around $40 \%$ of AccelTag transmissions from tagged fish that stayed in the study area were logged by the acoustic receiver array. The Lusitanian toadfish exhibited low activity during late summer and early autumn $(<3 \%$ of time active). The tidal stage and time of day were important factors that influenced the species behaviour and activity. Increased burrowing and re-burrowing movements were registered during spring tides, while attacks prevailed on neap tides and during the night. The tidal cycle only influenced toadfish behaviour and activity in interaction with time of day, with more attacks and higher levels of activity during nocturnal high tides.

Conclusions: Higher activity levels and attacks displayed by the Lusitanian toadfish during the night, at high tide periods and during Spring tides are considered to be associated with increased activity and vulnerability of its prey during these periods. The AccelTag proved to be a powerful tool to assess and monitor the activity and fine-scale behaviour of fish in situ. This technology is particularly suited for fish species with biological and ecological features similar to Lusitanian toadfish, i.e., resident species with low activity levels and behaviours with a distinct 3D acceleration signature.
\end{abstract}

Keywords: Halobatrachus didactylus, Batrachoididae, Biotelemetry, Accelerometer tag, Biologger, Mira estuary, Portugal

*Correspondence: bsquintella@fc.ul.pt

${ }^{1}$ MARE-Centro de Ciências do Mar e do Ambiente, Faculdade de Ciências da Universidade de Lisboa, Campo Grande, 1749-016 Lisbon, Portugal

Full list of author information is available at the end of the article

\section{Background}

Understanding fish behaviour and activity patterns is crucial to comprehend the biology and ecology of a fish species or the fish community of a particular ecosystem. In the field, locomotor activity is often inferred from capture in fishing gear and feeding activity is usually assessed from gut fullness at the moment of capture [1]. On the 
other hand, fish behaviour is often studied by direct observations, either on-site or in experimental tanks [1-3]. However, with the advancements of fish telemetry in the past decade, several behavioural and environmental variables can be monitored remotely $[4,5]$. A significant part of these studies involves archival tags [6,7], and acoustic transmitters equipped with a three-axis sensor [8-11].

Combining the features of archival tags and acoustic transmitters, the AccelTag was successfully developed and tested [5]. This acoustic three-axis accelerometer transmitter measures acceleration in all three directions (forward, lateral, and vertical). In addition, it also measures roll-independent pitch/tilt angle and roll around the fish's axis. The novelty of the AccelTag is that it has the measuring capabilities of an accelerometer archival tag, but without the necessity of recapture the tagged fish since it has the ability to analyse the logged data (algorithm), extract very detailed species-dependent information and transmit the relevant processed data [5]. Therefore, this tag is able to autonomously identify and record specific patterns (i.e., signatures) of different movements or behaviours. Due to its proven effectiveness [5], this technology was selected to study the finescale behaviour of the Lusitanian toadfish Halobatrachus didactylus (Bloch \& Schneider 1801).

Lusitanian toadfish reaches over $50 \mathrm{~cm}$ in total length, and it is one of the biggest members of the Batrachoididae taxonomic Family [12]. The geographical distribution area is vast, encompassing the Central and Northeast Atlantic Ocean, from the Gulf of Guinea to the Central Iberian Peninsula, and the Western Mediterranean Sea $[13,14]$. The species inhabits marine coastal waters, estuaries and open littoral lagoons living at depths up to $50 \mathrm{~m}$ or more, maintaining a benthic behaviour [15]. It is mostly found in muddy and sandy bottoms, where it may rest partially buried, but is also found concealed in hard substrata, using stones or rock crevices as shelters and nesting sites [16].

The species is more active in late spring and early summer, concurring with the reproductive period $[17,18]$. It occupies a top position on the food web [19] and exhibits a high degree of trophic plasticity, adapting its feeding habits to prey availability reproductive needs $[17,20,21]$. The specimens of this species remain most of the time buried or concealed in crevices, adopting a camouflage and ambush mode of predation [22, 23]. However, in the absence of prey or when the conditions are favourable, they perform an active search for food by sweeping the bottom and the water column, consuming a high percentage of necktobenthic organisms [22]. Stomach contents analysis suggested that such variations on activity may be related to temperature, light and tidal cycles [22].
Although Lusitanian toadfish is usually considered relatively sedentary, using mark-recapture procedures [22], it was found that some individuals might perform important displacements, which may have feeding or reproductive purposes. In the past, seasonal and daily patterns of activity of Lusitanian toadfish were roughly assessed with estimates of the yield of captures using trawling nets or feed intake cycles [22, 24]. However, these methodologies showed important limitations because the seasonal patterns of activity obtained were fairly masked by the recruitment of young-of-the-year and the differential level of avoidance of the fishing gears by the specimens in different light (i.e., visibility) and tide conditions, together with the differential rate of digestion of the different prey. Previous studies tagging toadfish with pressure and temperature data storage tags (DSTs) and acoustic transmitters in the Mira estuary (Southwest Portugal) confirmed that some individuals might perform important displacements (more than $17 \mathrm{~km}$ ) and that the species activity is influenced by the circadian cycle, tidal stage and tidal cycle [23]. The study also reinforced the idea that Lusitanian toadfish may not exclusively adopt a sit-and-wait predation behaviour, but probably undertakes an active search for food. However, the DSTs and acoustic transmitters did not allow detecting all the movements performed, identify their type and understand which of those were related to feeding. Additionally, the effort to recapture the tagged individuals to be able to download the information recorded by the DSTs was considerable [23] and this is a major limitation when working with DSTs particularly when dealing with aquatic animals.

Considering that the species has previous extensive research that also includes the use of biologgers, the adoption of the AccelTag to comprehend further the behaviour and trophic ecology of the species offers the opportunity to solidify the species knowledge and, at the same time, to evaluate in situ the adequacy of the threeaxis accelerometer acoustic transmitter.

\section{Materials and methods \\ Study site and acoustic receiver array}

The study was carried out in the Mira estuary, a relatively small brackish water system in the southwest coast of Portugal (coordinates WGS84: $8^{\circ} 46^{\prime} 19^{\prime \prime} \mathrm{W} ; 37^{\circ} 43^{\prime} 33^{\prime \prime} \mathrm{N}$ ). Six biotelemetry acoustic receivers (VR2W, VEMCO) were deployed $\sim 200 \mathrm{~m}$ apart from each other, covering a distance of ca. $1.5 \mathrm{~km}$, to detect the transmitted codes (Fig. 1). Every 15 days, the receivers were retrieved for data download and deployed again.

\section{AccelTag and fish tagging}

The AccelTag is an acoustic transmitter with a sensor (three-axis accelerometer) capable of measuring 


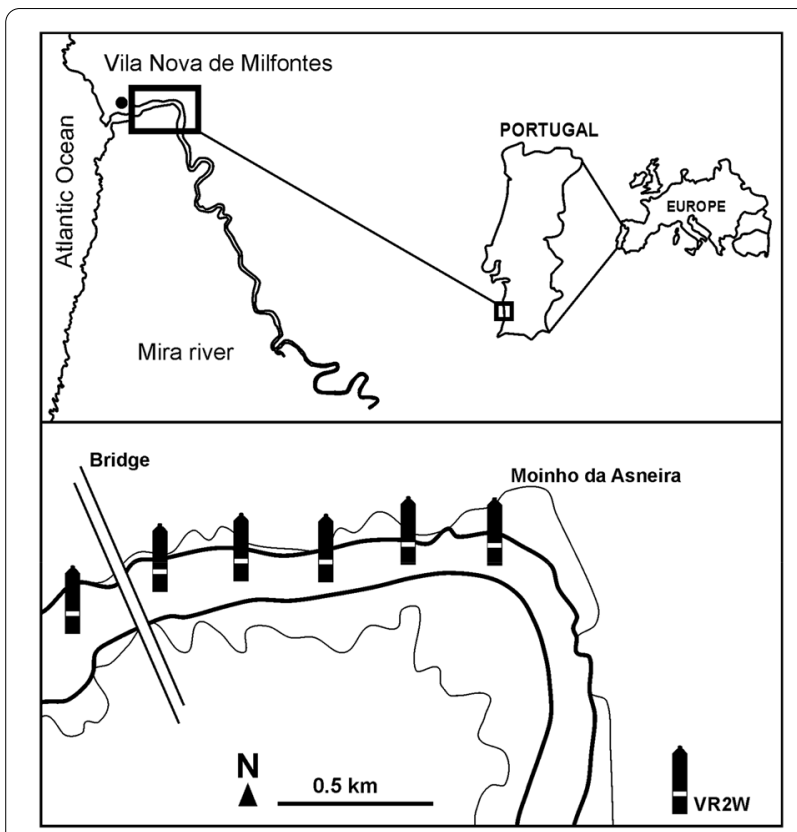

Fig. 1 Location of the study area and biotelemetry acoustic receivers (VR2W) array

forward, lateral and vertical accelerations as well as tilt and roll angles [5]. The AccelTag was developed to detect particular behaviours of the Lusitanian toadfish. The version of the AccelTag that was used is capable of identifying three behavioural signatures: attack towards a potential prey, burrowing and re-burrowing movements. The attack detection feature was tested with different types of prey, but the tag could not distinguish them. Moreover, although the behaviour is identified and registered as an attack, the predation's success rate is unknown [5].

The Acceltag detects and counts events for hourly periods, after which the data are acoustically transmitted through two consecutive S256 codes and recorded by an acoustic receiver array. The tag could report 0-6 events correctly, but if the number of events was 7 or more, the number 7 was logged. More than 7 events in one hour were not very likely to happen with this species [23]. The AccelTag also comprises an activity meter programmed and tested according to Lusitanian toadfish movements that measure the percentage of time the fish are moving. The activity data is transmitted as percentage intervals (Table 1).

Prior to the field study, a 13-mm AccelTag with the latest version of the "signature" detection software was externally implanted in 4 toadfish and tested for accuracy in a $900-\mathrm{L}$ sand bottom covered trial tank using an identical experimental protocol as previously described [5]. After satisfactory results were obtained, 9-mm AccelTags
Table 1 Sensor activity codes

\begin{tabular}{lc}
\hline Code & Time of activity (\%) \\
\hline 0 & $0.00-0.99$ \\
1 & $1.00-1.99$ \\
2 & $2.00-2.99$ \\
3 & $3.00-3.99$ \\
4 & $4.00-4.99$ \\
5 & $5.00-5.99$ \\
6 & $6.00-6.99$ \\
7 & $7.00-7.99$ \\
8 & $8.00-12.49$ \\
9 & $12.50-24.99$ \\
10 & $25.00-37.49$ \\
11 & $37.50-49.99$ \\
12 & $50.00-62.49$ \\
13 & $62.50-74.99$ \\
14 & $75.00-87.49$ \\
15 & $87.50-99.99$ \\
\hline
\end{tabular}

Each transmitted code corresponds to the percentage of time (interval) during which each toadfish was active in the past hour

were reprogrammed by Thelma Biotel. Tagging was external, according to the procedure described in [5].

A total of 24 Lusitanian toadfish ranging between $27.3 \mathrm{~cm}$ and $32.6 \mathrm{~cm}$ were captured using fish traps on two distinct occasions: 12 specimens in August 2010 (Group 1) and 12 in October 2010 (Group 2). Group 1 was tested from August 23 to September 24 and Group 2 from October 1 to November 3. The considered periods allowed to avoid the influence of the reproductive cycle (Spring and beginning of Summer). All Lusitanian toadfish were captured and released in Mira estuary within range of the VR2W array. After capturing, fish were immediately tagged with 9-mm versions of the AccelTag with approximately 1 month of battery life and released at the capture site.

\section{Data analysis}

The success rate of transmissions detected by the acoustic receivers array was calculated by dividing the number of transmissions received by the total number of transmissions theoretically emitted by the tag. This was only calculated for the duration of the study period during which tagged specimen maintained position within range of the acoustic receiver array. The influence of environmental factors on the activity and behaviour of toadfish was analysed using a factorial ANOVA. The analysed environmental factors were tidal stage (spring vs neap), tidal cycle (high vs low) and time of day (day vs night). Also, the influence of the time of the year was studied comparing the differences between Group 1 (summer) and 
Group 2 (autumn). This procedure allowed to assess each factor's influence or, as an interaction of two or more factors. The data used in the analysis were expressed as the total number of events per fish and hour for each behavioural signature. Activity data was converted from percentage to time units (minutes), and the lower limit of the activity interval per hour and per fish was used for the analysis. As an example, if the data showed an activity interval of 3 (5\%)-3.6 (5.99\%) minutes, it was used $3 \mathrm{~min}$ of activity for the analysis. Spring tides were defined as tides with an amplitude of over $3.2 \mathrm{~m}$ and neap tides as tides of amplitude less than $2 \mathrm{~m}$. For tidal cycle analysis, it was considered the transmissions detected $2 \mathrm{~h}$ before and $2 \mathrm{~h}$ after low and high tidal peaks. Night-time included dusk and day-time included dawn. In order to obtain the most accurate data possible, codes from the first 2 days and the last day of transmissions were removed from the analysis [5].

\section{Results}

Before the field study, the tag and detection software were tested for accuracy on four specimens in a laboratory trial. Tests resulted in $100 \%$ efficiency for detecting activity, burrowing and re-burrowing movements. Attacks towards potential prey were registered with $85 \%$ accuracy, increasing $25 \%$ when compared with the previous algorithm developed by [5].

Regarding the field study, of the 24 Lusitanian toadfish tagged and released in the Mira estuary, only three specimens spent most of the time out of the range of the acoustic receiver array. The remaining specimens returned to the capture sites within 2 days and remained most of the time inside a perimeter of $200 \mathrm{~m}$.

A total of 3530 (39.5\% of the transmissions) complete codes from Group 1 and 3719 (41.7\%) from Group 2 were successfully received, stored, and downloaded from the acoustic telemetry array. Group 1 performed 960 potential attacks, 202 burrowings and 282 re-burrowings, and showed $1.51 \mathrm{~min}$ ( $2.5 \%$ of the time) per hour of minimum mean activity. Group 2 conducted 665 potential attacks, 120 burrowings and 142 re-burrowings, and had a minimum mean activity of $1.52 \mathrm{~min}$ per $\mathrm{h}$ ( $2.5 \%$ of the time).

By plotting the frequency of each studied behaviour and the percentage of activity against tidal amplitude, it was possible to observe that the frequency of attacks, burrowing and re-burrowing movements varied along the studied period but without an obvious relation with tidal stage per se (Figs. 2 and 3). Regarding activity patterns, Lusitanian toadfish from Group 1 tracked in the summer were more active during spring tides, whereas fish from Group 2 tracked in autumn did not reveal a marked activity pattern throughout the study period (Figs. 2 and 3).
Considering the activity and the number of events observed during distinct environmental conditions, tidal stage (TS: spring vs neap) and time of day (TD: day vs night) were the most influencing factors (Tables 2, 3). In fact, tagged Lusitanian toadfish were more active and performed significantly more burrowing and reburrowing movements during spring tides. However, the TS did not influence the number of attacks significantly (Tables 2, 3). Regarding the influence of time of day, Lusitanian toadfish were more active and performed significantly more attacks during night-time (Tables 2,3 ).

When evaluating differences in behaviour potentially associated with seasonality, the number of attacks and activity revealed no statistical differences between groups/seasons. However, Group 1 composed by fish tracked during the summer performed significantly more burrowings and re-burrowings than Group 2 composed by fish tracked in autumn (Tables 2, 3).

Even though tidal cycle (TC: high vs low) alone did not significantly influence the behaviour and activity of the Lusitanian toadfish, factorial ANOVA showed a significant interaction between this factor and the TD regarding the number of attacks and fish activity (Table 3 ). The analyses of Tables 2 and 3 show that toadfish performed more attacks and were more active during high tides that occurred during night-time. The TS also significantly influenced toadfish behaviour when interacting with TD. Indeed, it was during the night-time of spring tides when toadfish were substantially more active (Tables 2,3 ). Significant interactions were also found between-group and TS, and between-group and TD. During the summer (Group 1) Lusitanian toadfish were more active and performed more burrowing and re-burrowing movements during spring tides, along with more attacks during the night-time.

\section{Discussion}

The results from this study were obtained using an innovative technological approach, the AccelTag, developed and previously tested in controlled laboratory conditions [5]. In the present work, it was used for the first time to obtain in situ detailed foraging behaviour data of an aquatic animal. AccelTag proved to be a powerful tool to assess and monitor the fine-scale behaviour of a resident estuarine fish. In terms of ecological data obtained with AccelTag, the main findings are concordant with results obtained with other works that used distinct methodological approaches to study the Lusitanian toadfish foraging behaviour [21-24]. When comparing to other available tools (see [5] for further discussion) such as data storage tags with accelerometer sensors $[6$, $7]$, and even more recent acoustic transmitters equipped with three-axis accelerometer sensors $[8-11,25,26]$, the 


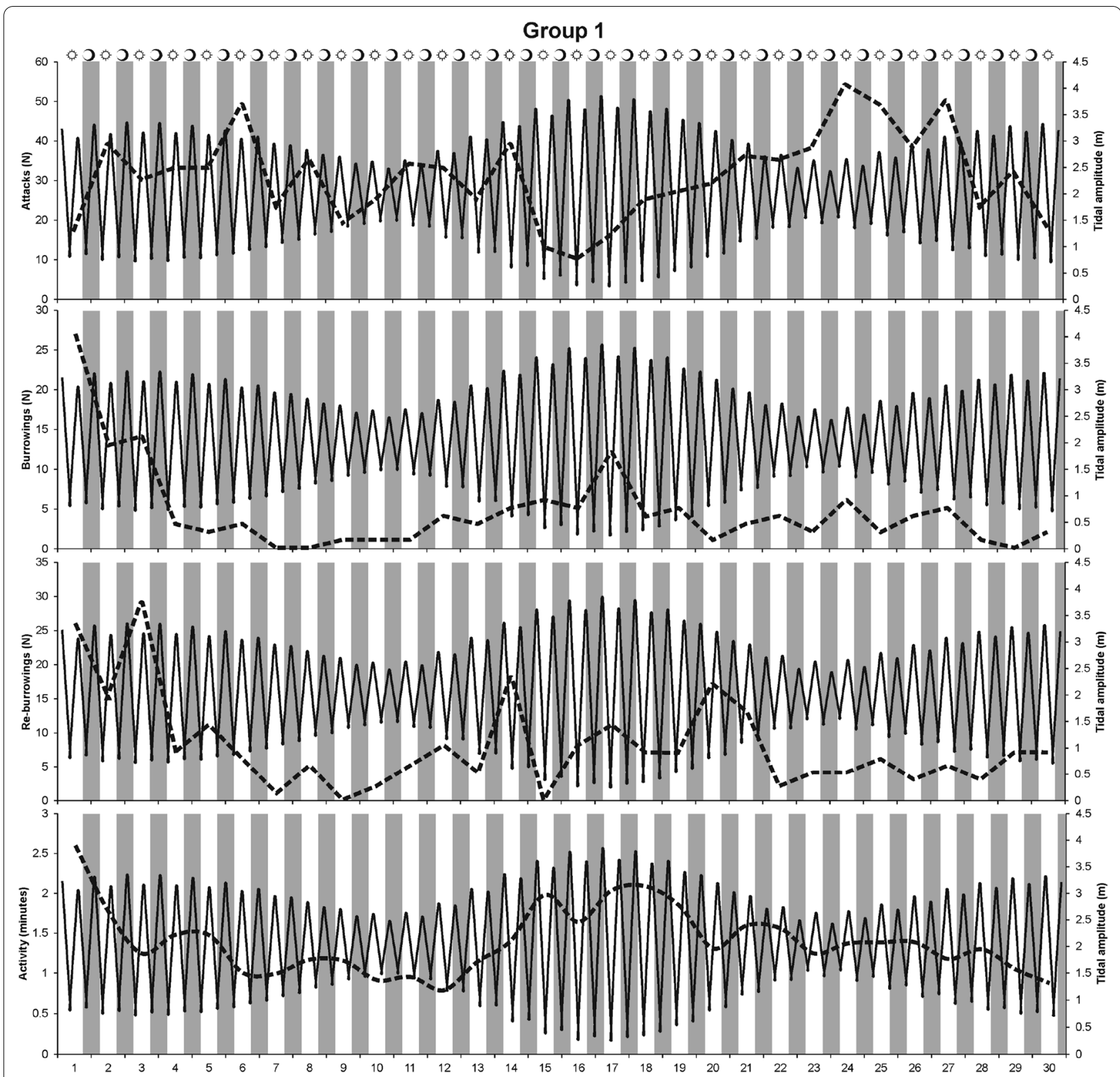

Fig. 2 Graphic representation of the studied behaviours as a function of the tidal stage (spring or neap tide) and time of day (day or night) for the toadfish of Group 1 tracked during August-September 2010

AccelTag has the advantage of being able to process the fine-scale acceleration information autonomously and acoustically transmit the correspondent behaviour. Several authors have identified advantages of data processing and compression, e.g., increased tag autonomy, reduced storage requirements and reduced data analysis time [11, 27]. Moreover, the work previously developed [5], combined with the present study corresponds to the anticipated studies and technological enhancements proposed [11], namely the tagging of captive specimens to calibrate the software accordingly to distinct behaviours, and then implement in situ behaviour studies.

With regard to the foraging ecology of the Lusitanian toadfish, tides and circadian cycle, together with the time of year, seem to play an essential role in the behaviour of this species. Notwithstanding being capable of swimming over relatively large distances [22, 23], specimens typically do not perform significant displacements and remain most of the time inactive $(97.5 \%$ of the time in the present study), buried in the sediment or concealed 


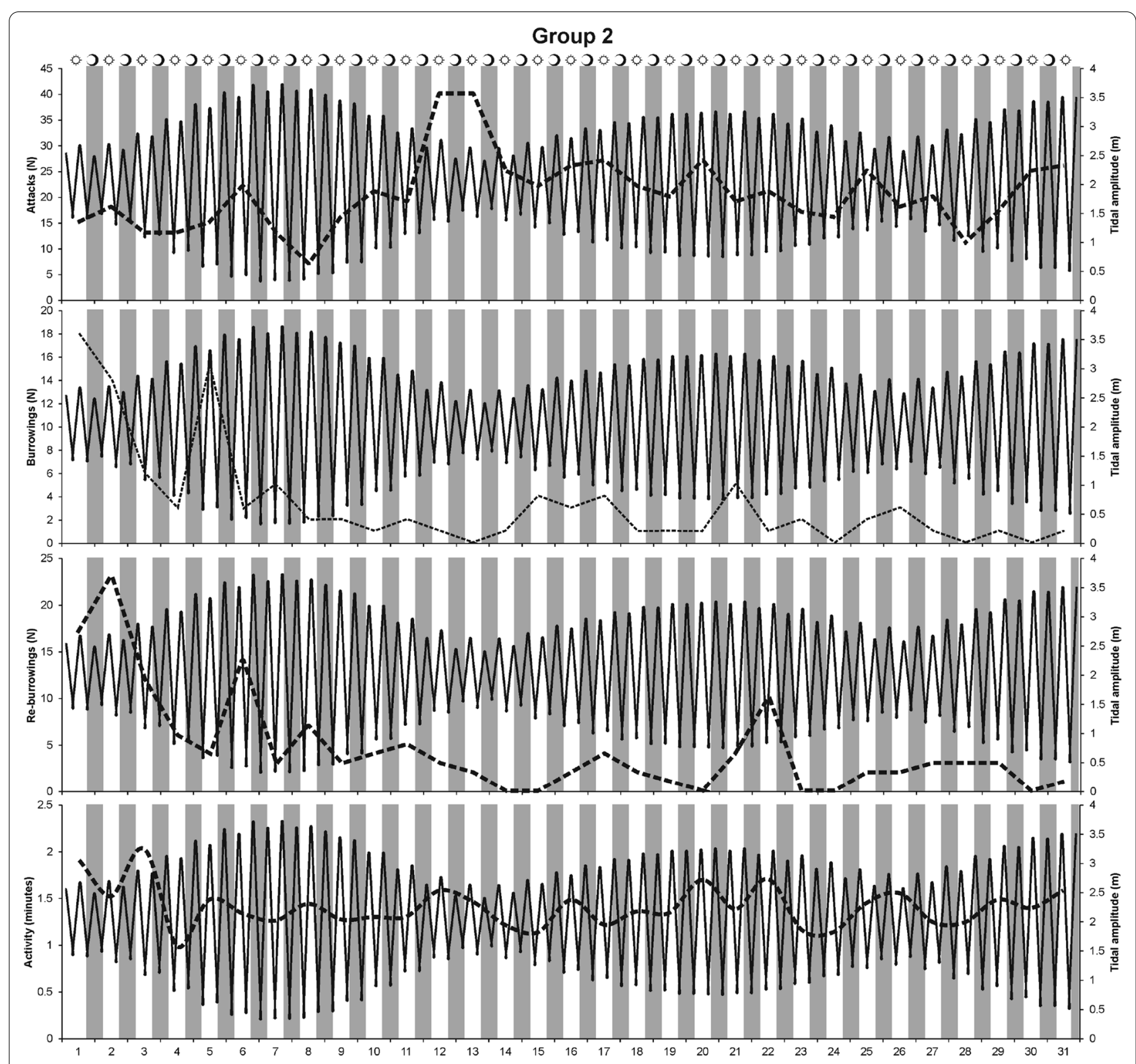

Fig. 3 Graphic representation of the studied behaviours as a function of the tidal stage (spring or neap tide) and time of day (day or night) for the toadfish of Group 2 tracked during October-November 2010

in rocky crevices. In fact, the majority of the specimens remained within the study area for almost the entire study period, some of them returning to the capture site after being tagged and released. However, this sedentary behaviour was amplified by the time of the year when the study occurred. Moreover, this species is more active during the spawning season, which occurs in late spring and early summer $[17,18]$, whereas this study was performed in late summer and mid-autumn when the specimens tend to reduce global activity and decrease the number of long displacements [22].
Tidal stage influenced toadfish behaviour and activity in larger cycles of time. During spring tides of higher amplitudes, the activity increased and the number of potential attacks diminished. This pattern may be related to strong water currents associated with this period that force toadfish to actively avoid being dragged away and, consequently, reduce feeding activity. After this period of reduced feeding attempts, during neap tides, attacks considerably increase and activity level decreases. Variations on tidal stages also explain the marked pattern of burrowing and re-burrowing movements. These are 
Table 2 Mean number of events and time of activity of the tagged toadfish according to environmental factors

\begin{tabular}{|c|c|c|c|c|c|c|c|c|c|c|c|c|}
\hline & \multicolumn{3}{|c|}{ Attack } & \multicolumn{3}{|c|}{ Burrowing } & \multicolumn{3}{|c|}{ Re-burrowing } & \multicolumn{3}{|l|}{ Activity } \\
\hline & $N$ & Mean & SD & $N$ & Mean & SD & $N$ & Mean & SD & Minute & Mean & SD \\
\hline \multicolumn{13}{|c|}{ Group 1} \\
\hline ST & 362 & 0.27 & 0.73 & 162 & 0.12 & 0.47 & 204 & 0.15 & 0.61 & 2708.4 & 2.00 & 4.29 \\
\hline NT & 598 & 0.27 & 0.66 & 40 & 0.02 & 0.14 & 78 & 0.04 & 0.25 & 2631.9 & 1.21 & 1.78 \\
\hline $\mathrm{LT}$ & 493 & 0.27 & 0.69 & 88 & 0.05 & 0.27 & 140 & 0.08 & 0.42 & 2564.1 & 1.44 & 2.54 \\
\hline $\mathrm{HT}$ & 467 & 0.27 & 0.68 & 114 & 0.06 & 0.34 & 142 & 0.08 & 0.45 & 2776.2 & 1.58 & 3.44 \\
\hline $\mathrm{Da}$ & 201 & 0.13 & 0.45 & 98 & 0.06 & 0.29 & 118 & 0.08 & 0.41 & 1264.8 & 0.79 & 1.55 \\
\hline $\mathrm{Ni}$ & 759 & 0.40 & 0.81 & 104 & 0.05 & 0.33 & 164 & 0.09 & 0.45 & 4074.5 & 0.11 & 3.73 \\
\hline \multicolumn{13}{|c|}{ Group 2} \\
\hline $\mathrm{ST}$ & 143 & 0.17 & 0.49 & 38 & 0.05 & 0.32 & 45 & 0.05 & 0.34 & 1089.6 & 1.31 & 2.09 \\
\hline NT & 522 & 0.18 & 0.54 & 82 & 0.03 & 0.25 & 97 & 0.03 & 0.25 & 4594.2 & 1.59 & 2.85 \\
\hline LT & 267 & 0.15 & 0.45 & 50 & 0.03 & 0.28 & 60 & 0.03 & 0.25 & 2810.7 & 1.56 & 3.05 \\
\hline $\mathrm{HT}$ & 398 & 0.21 & 0.59 & 70 & 0.04 & 0.25 & 82 & 0.04 & 0.29 & 2873.1 & 1.50 & 2.32 \\
\hline $\mathrm{Da}$ & 190 & 0.11 & 0.41 & 51 & 0.03 & 0.19 & 74 & 0.04 & 0.24 & 1764.9 & 1.04 & 2.02 \\
\hline $\mathrm{Ni}$ & 475 & 0.24 & 0.60 & 69 & 0.03 & 0.32 & 68 & 0.03 & 0.29 & 3918.9 & 1.94 & 3.10 \\
\hline \multicolumn{13}{|l|}{ Total } \\
\hline ST & 505 & 0.22 & 0.61 & 200 & 0.09 & 0.40 & 249 & 0.10 & 0.48 & 3798.0 & 1.66 & 3.19 \\
\hline NT & 1120 & 0.23 & 0.60 & 122 & 0.03 & 0.20 & 175 & 0.05 & 0.25 & 7226.1 & 1.40 & 2.32 \\
\hline LT & 760 & 0.21 & 0.57 & 138 & 0.04 & 0.28 & 200 & 0.06 & 0.34 & 5374.8 & 1.50 & 2.80 \\
\hline $\mathrm{HT}$ & 865 & 0.24 & 0.64 & 184 & 0.05 & 0.30 & 224 & 0.06 & 0.37 & 4649.3 & 1.54 & 2.88 \\
\hline $\mathrm{Da}$ & 391 & 0.12 & 0.43 & 139 & 0.05 & 0.24 & 192 & 0.06 & 0.33 & 3029.7 & 0.92 & 1.79 \\
\hline $\mathrm{Ni}$ & 1234 & 0.32 & 0.71 & 143 & 0.04 & 0.33 & 232 & 0.06 & 0.37 & 7993.4 & 1.03 & 3.42 \\
\hline
\end{tabular}

$N$ number of events (attacks, burrowings and re-burrowings) and mean time of activity (minutes) per hour, SD standard deviation, ST spring tides, NT neap tide, $L T$ low tide, $H T$ high tide, Da day, Ni night

Table 3 Factorial ANOVA results to assess the influence of environmental factors on the activity and behaviour of the tagged toadfish

\begin{tabular}{|c|c|c|c|c|}
\hline & \multicolumn{4}{|l|}{ Factorial ANOVA } \\
\hline & Attacks & Burrowing & Re-burrowing & Activity \\
\hline Global & $F=18.883 ;$ d.f. $=15 ; p<0.01$ & $F=9.864 ; d . f .=15 ; p<0.01$ & $F=8.370 ; d . f .=15 ; p<0.01$ & $F=29.517 ; d . f .=15 ; p<0.01$ \\
\hline TS & $F=0.003 ;$ d.f. $=1 ; p=0.958$ & $F=61.611 ; d . f .=1 ; p<0.01$ & $F=49.191 ; d . f .=1 ; p<0.01$ & $F=13.832 ; d . f .=1 ; p<0.01$ \\
\hline TC & $F=1.921 ; d . f .=1 ; p=0.166$ & $F=1.506 ; d \cdot f .=1 ; p=0.220$ & $F=0.583 ; d \cdot f .=1 ; p=0.445$ & $F=2.903 ; d . f=1 ; p=0.09$ \\
\hline TD & $F=138.887 ;$ d.f. $=1 ; p<0.01$ & $F=0.000 ; d . f .=1 ; p=0.993$ & $F=0.195 ; d . f .=1 ; p=0.658$ & $F=248.599 ; d . f .=1 ; p<0.01$ \\
\hline G & $F=31.572 ;$ d.f. $=1 ; p=0.05$ & $F=20.140 ; d . f .=1 ; p<0.01$ & $F=27.775 ; d . f .=1 ; p<0.01$ & $F=3.744 ; d . f .=1 ; p=0.05$ \\
\hline TS * TC & $F=0.042 ; d . f .=1 ; p=0.838$ & $F=1.875 ; d . f .=1 ; p=0.171$ & $F=0.176 ; d . f .=1 ; p=0.675$ & $F=7.131 ; d . f .=1 ; p=0.08$ \\
\hline $\mathrm{TS} * \mathrm{TD}$ & $F=2.657 ; d . f .=1 ; p=0.103$ & $F=0.040 ; d . f .=1 ; p=0.842$ & $F=1.228 ; d \cdot f .=1 ; p=0.268$ & $F=5.539 ; d . f .=1 ; p<0.05$ \\
\hline$T S * G$ & $F=0.051 ; d . f .=1 ; p=0.822$ & $F=33.601 ; d . f .=1 ; p<0.01$ & $F=25.382 ; d . f .=1 ; p<0.01$ & $F=53.695 ; d . f .=1 ; p<0.01$ \\
\hline $\mathrm{TC} * \mathrm{TD}$ & $F=4.216 ; d . f .=1 ; p<0.05$ & $F=0.103 ; d . f .=1 ; p=0.748$ & $F=0.953 ; d . f .=1 ; p=0.329$ & $F=12.149 ; d . f .=1 ; p<0.01$ \\
\hline $\mathrm{TC} * \mathrm{G}$ & $F=2.730 ; d . f .=1 ; p=0.10$ & $F=0.267 ; d . f .=1 ; p=0.605$ & $F=0.465 ; d \cdot f .=1 ; p=0.495$ & $F=1.325 ; d . f .=1 ; p=0.250$ \\
\hline$G * T D$ & $F=21.913 ; d . f .=1 ; p<0.01$ & $F=0.708 ; d . f .=1 ; p=0.400$ & $F=2.234 ; d . f .=1 ; p=0.135$ & $F=15.885 ; d . f .=1 ; p<0.01$ \\
\hline
\end{tabular}

TS tidal stage, TC tidal cycle, TD time of day, G group

Significant differences for $p<0.01$ and $p<0.05$.

more frequent during spring tides, when toadfish need to refuge (i.e., remain buried) to avoid being displaced by strong water currents, and decrease during neap tides.
On the other hand, the tidal cycle only influenced toadfish behaviour and activity in interaction with the time of day. Indeed, the number of attacks and activity were influenced synergistically by those two factors. Toadfish 
were more active during night-time, confirming previous findings in the same estuary [22, 23]. The nocturnal period is the preferred for engaging feeding activities as their prey are also more active. Subsequently, the number of attacks also increased during the night period. Additionally, high tide phases considerably improve visibility in the lower Mira Estuary due to the input of more transparent water from the ocean. As previously observed in laboratory experiments [5], toadfish is a visual predator attacking its prey mostly based on movement. Therefore, the combination of high tide with night-time results in a favourable period for toadfish to feed. As highlighted by [23] these higher activity periods displayed by the Lusitanian toadfish are not independent of the activity of its prey, most of them displaying higher activity or vulnerability to predation during the night and at high tide periods.

The influence of the time of year was evident in the differences between the two groups of toadfish tagged. The first group of toadfish was tagged and tested in late summer, close to the end of the spawning season. Moreover, the year of 2010 presented a relatively rainy and cold spring, which delayed the spawning season of this species, which is highly influenced by water temperature [22]. Therefore, global activity is relatively high at the beginning of the study, gradually reducing in the following 12 days. During this period, the tagged toadfish also performed more attacks, as it is expected at the end of the reproductive period [22]. Concerning the second group of toadfish, it was monitored in mid-autumn, far from the spawning season and closer to the winter. This period corresponds to the time of year when this species is less active [22]. This discrepancy between the times of the year in which the two groups were monitored may explain detected differences in burrowing and re-burrowing movements and activity levels, with toadfish tracked in summer performing more of these behaviours and toadfish tracked in autumn being globally more active. However, the number of attacks did not significantly differ between seasons, which may suggest that the higher activity observed with the toadfish tracked in autumn may be related to the search for shelters instead of food. Therefore, both groups were influenced by tide and time of day, but differences between groups are probably related to the species circannual lifecycle.

\section{Conclusions}

The behavioural signature capture version of the AccelTag was tested for the first time in situ to monitor the fine-scale behaviour of aquatic animals. This technology proved to be particularly suited for fish species with biological and ecological features similar to the Lusitanian toadfish, i.e., resident species with low activity levels and behaviours with a distinct threeaxis acceleration signature. Higher activity levels and attacks displayed by the Lusitanian toadfish during the night, at high tide periods and during Spring tides are considered to be associated with increased activity and vulnerability of its prey during these periods. The potentialities of this technology to study aquatic organisms behaviour are far from being fully explored with this study. More precise and complete signature detection algorithms, together with longer battery life could offer new possibilities of behavioural studies on the Lusitanian toadfish and other fish species. In the future, it would be interesting to discern between successful and unsuccessful attacks or even the type of prey, once toadfish may attack and handle distinct preys differently.

\section{Acknowledgements}

The present study was carried under the project "AccelTag-Development of an acoustic three-axis accelerometer transmitter for marine species" funded by European Union EUREKA Eurostars Programme and project "COASTNET_ Portuguese Coastal Monitoring Network (PINFRA/22128/2016)" funded by European Regional Development Fund (FEDER), through LISBOA2020 and ALENTEJO2020 regional operational programs, in the framework of the National Roadmap of Research Infrastructures of strategic relevance.

\section{Authors' contributions}

PRA, BRQ, AG and JLC conceived and designed the project. TJP and BRQ led the field work. Data analysis was conducted by TJP with help from JLC, PRA and $B R Q$. All authors (JLC, PRA, BRQ, AG, MJC, JPM and JLC) contributed to the research and writing of the manuscript. All authors read and approved the final manuscript.

\section{Funding}

Research was funded by European Union EUREKA Eurostars Programme.

\section{Availability of data and materials}

The datasets used and analysed during the current study are available from the corresponding author on reasonable request.

\section{Ethics approval and consent to participate}

This study was carried out in strict accordance with the recommendations present in the Guide for the Care and Use of Laboratory Animals of the European Union—in Portugal represented by the Decree-Law No. 129/92, Portaria No. 1005/92. Approval by a named review board institution or ethics committee was not necessary as the final model for ethical experimentation using fish as biological models was not implemented in Portuguese research units at the time of experimentation.

\section{Consent for publication}

Not applicable.

\section{Competing interests}

The authors declare that they have no competing interests.

\section{Author details}

${ }^{1}$ MARE-Centro de Ciências do Mar e do Ambiente, Faculdade de Ciências da Universidade de Lisboa, Campo Grande, 1749-016 Lisbon, Portugal. ${ }^{2}$ Departamento de Biologia, Escola de Ciências e Tecnologia, Universidade de Évora, Évora, Portugal. ${ }^{3}$ Departamento de Biologia Animal, Faculdade de Ciências da Universidade de Lisboa, Lisboa, Portugal. ${ }^{4}$ Thelma Biotel, Sluppen, Trondheim, Norway. 
Received: 17 September 2020 Accepted: 27 January 2021

Published online: 02 March 2021

\section{References}

1. Reebs SG. Plasticity of diel and circadian activity rhythms in fishes. Rev Fish Biol Fisher. 2002;12:349-71.

2. Martins CIM, Conceição LEC, Schrama JW. Consistency of individual variation in feeding behaviour and its relationship with performance traits in Nile tilapia Oreochromis niloticus. Appl Anim Behav Sci. 2011;133:109-16.

3. Ramos A, Fonseca PJ, Modesto T, Almada VC, Amorim MPC. Alloparental behavior in the highly vocal Lusitanian toadfish. J Exp Mar Biol Ecol. 2012;435:58-62.

4. Hussey NE, Kessel ST, Aarestrup K, Cooke SJ, Cowley PD, Fisk AT, Harcourt RG, Holland KN, Iverson SR, Kocik JF, Flemming JEM, Whoriskey FG. Aquatic animal telemetry: a panoramic window into the underwater world. Science. 2015;348(6240):1255642.

5. Almeida PR, Pereira TJ, Quintella BR, Gronningsaeter A, Costa MJ, Costa $J$ L. Testing a 3-axis accelerometer acoustic transmitter (AccelTag) on the Lusitanian toadfish. J Exp Mar Biol Ecol. 2013;449:230-8.

6. Gleiss AC, Gruber SH, Wilson RP. Multi-channel datalogging: towards determination of behaviour and metabolic rate in free-swimming sharks. In: Nielsen JL, Arrizabalaga H, Fragoso N, Hobday A, Lutcavage M, Sibert J, editors. Tagging and tracking of marine animals with electronic devices. Dordrecht: Springer; 2009. p. 211-28.

7. Ward CRE, Bouyoucos IA, Brooks EJ, O'Shea OR. Novel attachment methods for assessing activity patterns using triaxial accelerometers on stingrays in the Bahamas. Mar Biol. 2019;166:53.

8. Gleiss AC, Dale JJ, Holland KN, Wilson RP. Accelerating estimates of activity-specific metabolic rate in fishes: testing the applicability of acceleration data-loggers. J Exp Mar Biol Ecol. 2010;385(1-2):85-91.

9. Murchie KJ, Cooke SJ, Danylchukc AJ, Suski CD. Estimates of field activity and metabolic rates of bonefish (Albula vulpes) in coastal marine habitats using acoustic tri-axial accelerometer transmitters and intermittent-flow respirometry. J Exp Mar Biol Ecol. 2011;396(2):147-55.

10. Nakamura I, Watanabe YY, Papastamatiou YP, Sato K, Meyer CG. Yo-yo vertical movements suggest a foraging strategy for tiger sharks Galeocerdo cuvier. Mar Ecol Prog Ser. 2011;424:237-46.

11. Nuijten RJM, Gerrits T, Shamoun-Baranes J, Nolet BA. Less is more: onboard lossy compression of accelerometer data increases biologging capacity. J Anim Ecol. 2020;89(1):237-47.

12. Greenfield DW, Winterbottom R, Collette BB. Review of the toadfish genera (Teleostei: Batrachoididae). San Francisco, CA, USA: California Academy of Sciences, Proc; 2008.

13. Beauchot ML. Poissons osseux. In: Fischer W, Schneider M, Beauchot M-L, editors. Fiches FAO d'identification des espèces pour les besoins de la pêche. Mediterranée et Mer Noire (Zone de Pêche 37). Revision 1. Vol. II-Vertebrés. FAO, Rome, 1987. p. 891-1421.

14. Costa JL, Costa MJ. Distribution and abundance of the Lusitanian toadfish Halobatrachus didactylus (Bloch \& Schneider, 1801) in Portugal with some remarks on its population fragmentation. Rev Biol. 2002;20:155-67.
15. Roux C. Batrachoididae. In: Fischer W, Bianchi G, Scott WB, editors. Fiches FAO d'identification des espèces pour les besoins de la pêche. Atlantique centreest: zones de pêche 34, 47 (en partie). Vol. I. Canada Fonds de Dépôt, Ottawa, 1981.

16. Muzavor S, Arruda LM, Andrade JP. Roteiro ecológico da Ria Formosa. vol. 2, Peixes. Foco Editora 1993.

17. Costa JL, Silva G, Almeida PR, Costa MJ. Activity and diet of Halobatrachus didactylus (Bloch \& Schneider, 1801) adults in the Tagus estuary. Thalassas. 2000;16:21-5

18. Palazón-Fernández JL, Arias AM, Sarasquete C. Aspects of the reproductive biology of the toadfish, Halobatrachus didactylus (Schneider, 1801) (Pisces: Batrachoididae). Scientia Marina. 2001;65(2):131-8.

19. Costa JL, Domingos I, Almeida AJ, Feunteun E, Costa MJ. The interaction between Halobatrachus didactylus and Anguilla anguilla: what happens when these species occur in sympatry? Cybium. 2008;32(2):111-7.

20. Pereira TJ, Silva G, Costa MJ, Costa JL. Life strategies of Halobatrachus didactylus (Bloch \& Schneider, 1801) in the Tagus estuary: comparison among different morphotypes. Estuar Coast Shelf Sci. 2011;93(4):328-35.

21. Félix P, Amorim M, Pereira T, Fonseca P, Sousa-Santos C, Costa J. Feeding ecology and life-history strategy of nesting males in a fish with long parental care, Lusitanian toadfish (Halobatrachus didactylus, Batrachoididae). J Mar Biol Assoc UK. 2016;96(3):657-65.

22. Costa JL. A biologia do xarroco, Halobatrachus didactylus (Bloch \& Schneider, 1801), e o seu papel na estruturação e funcionamento das comunidades em que se insere; referência especial à população do Estuário do Mira. PhD Thesis, University of Lisbon, Lisbon, 2004.

23. Campos MC, Costa JL, Quintella BR, Costa MJ, Almeida PR. Activity and movement patterns of the Lusitanian toadfish inferred from pressure sensitive data-loggers in the Mira estuary (Portugal). Fish Manag Ecol. 2008;15(5-6):449-58.

24. Cotter JC, Pereira TJ, Costa MJ, Costa JL. Distribution, abundance, population structure and activity of Halobatrachus didactylus (Bloch \& Schneider, 1801) in the Tagus estuary and adjacent coastal area. J Mar Biol Assoc. 2013;93(2):405-12.

25. O'Toole AC, Murchie KJ, Pullen C, Hanson KC, Suski CD, Danylchuk AJ, Cooke SJ. Locomotory activity and depth distribution of adult great barracuda (Sphyraena barracuda). In: Bahamian coastal habitats determined using acceleration and pressure biotelemetry transmitter. Mar Freshw Res 2010;61(12):1446-1456.

26. Kneebone J, Winton M, Danylchuk A, Chisholm J, Skomal G. An assessment of juvenile sand tiger (Carcharias taurus) activity patterns in a seasonal nursery using accelerometer transmitters. Environ Biol Fish. 2018;101(8):1739-56.

27. Allen AN, Goldbogen JA, Friedlaender AS, Calambokidis J. Development of an automated method of detecting stereotyped feeding events in multisensor data from tagged rorqual whales. Ecol Evol. 2019;6(20):7522-35.

\section{Publisher's Note}

Springer Nature remains neutral with regard to jurisdictional claims in published maps and institutional affiliations.

\footnotetext{
Ready to submit your research? Choose BMC and benefit from:

- fast, convenient online submission

- thorough peer review by experienced researchers in your field

- rapid publication on acceptance

- support for research data, including large and complex data types

- gold Open Access which fosters wider collaboration and increased citations

- maximum visibility for your research: over $100 \mathrm{M}$ website views per year
}

At BMC, research is always in progress.

Learn more biomedcentral.com/submissions 